E-ISSN: 2808-5361 http://e-journal.fkmumj.ac.id/
Proceeding The First

Muhammadiyah

Internasional- Public Health

and Medicine Conference

\title{
SYSTEMATIC REVIEW: BLOOD PRESSURE VALUE DIFFERENCE BETWEEN MEASUREMENT WITH OSCILLOMETRIC AND AUSCULTATION OF PATIENTS IN HEALTH SERVICES
}

\author{
Dikalita Utami Putri \\ Master of Public Health, Faculty of Public Health, Muhammadiyah University of Jakarta
}

\begin{abstract}
Blood pressure is a vital sign that is very important and is a basic physiological parameter in conducting physical assessments of critical patients. Blood pressure can be measured using manual or automatic instruments. The gold standard measures blood pressure with a mercury sphygmomanometer, but its use has been withdrawn due to the risk of mercury contamination. In practice, different values are often obtained between the oscillometric method and auscultation. The objective of this review is to evaluate the significant difference in blood pressure between using the oscillometric method and auscultation in patients in health care. Method A systematic review approach is carried out on research results published in 3 search engines, namely EBSCO, Proquest, and Science Direct. Articles found according to the inclusion criteria that have been set are then assessed using the level of evidence using the NICE approach. The appraisal study uses the Critical Appraisal Skills Program (CASP), and the synthesis method uses a modified PICO. The result indicates that a total of 3 (three) studies were obtained according to the inclusion criteria. The intervention carried out was measuring blood pressure using two methods, namely oscillometric and auscultation. To sum up, there was a statistically significant difference in systolic pressure between the oscillometric and auscultatory methods.
\end{abstract}

Keywords: Blood pressure, oscillometric, and auscultation 


\section{INTRODUCTION}

Measurement and recording of the patient's vital signs are an integral part of observing and managing the patient's condition. Measurement of blood pressure is a form of identification and anticipation of significant findings related to circulation problems. Critical patients in particular often have fluctuations in blood pressure, which is an indication of a life threat related to changes in patient status. An example of a case is the condition of hypotension/very low blood pressure in critically ill patients, which is an indication of hypovolemia, sepsis, or cardiogenic shock (Hinckley and Walker, 2005). Identification of blood pressure can help lower cardiovascular risk and prevent target organ damage. Inaccurate blood pressure measurement can lead to misclassification of blood pressure, either normal, hypotension, or hypertension, leading to mismanagement of patient medication (Jones, 2001; Pickering, 2002).

Blood pressure can be measured using an oscillometric instrument and a sphygmomanometer. Measurements with a mercury sphygmomanometer can maintain greater accuracy because of its non-mechanical design. Mercury is the gold standard in the accuracy of blood pressure measurements in both in-clinic and out-of-clinic settings (Pickering, 2005). However, (Baillie, 2005; Valler-Jones and Wedgbury, 2005) explain that the accuracy of the auscultation method can be influenced by human error factors, which include decreased hearing, impaired concentration, and a noisy environment. An interobserver study showed that manual blood pressure measurements in 140 emergency room patients using observation methods performed by different people on the same subject got different measurement results (Edmonds, 2002). Therefore, the oscillometric method is more often used in nursing services in ordinary care rooms, which is an action that is often carried out in monitoring the patient's condition.

Oscillometric Measurements detect various pressure produced by the arterial wall under the cuff, which the oscillating machine can read. This method can measure systolic, diastolic, and mean arterial pressure (MAP) (MHRA, 2006). The use of oscillometric has the advantages of being more accurate, requires a relatively short time, saves nursing staff, and requires less concentration in operating it. In addition to this, oscillometric can also continue to measure blood pressure without interference in noisy conditions and measure dimmed pulse pressure in obese patients (Staessenet al. 1995). However, several studies related to the use of oscillometric have found data that needs serious attention. The British Hypertension Society (BHS) found that oscillometric had an error $>15 \mathrm{mmHg}$ by $5 \%$ throughout their use. An error of $10 \mathrm{mmHg}$ has the potential to cause misclassification of blood pressure in 100,000 adult patients in the UK (MHRA 2003). 
E-ISSN: 2808-5361

http://e-journal.fkmumj.ac.id/
Proceeding The First

Muhammadiyah

Internasional- Public Health and Medicine Conference

One of the disadvantages of using oscillometric is arrhythmias case because of the wide range of variations in blood pressure over time. An example of such a case is in a patient with atrial fibrillation whose blood pressure and stroke volume vary depending on the previous pulse interval. This condition cannot be detected by oscillometric (Beevers et al. 2001). Another study conducted by Ireland (2001) on 48 normotensive patients showed hypertension and required hypertension therapy when measured using electronic methods.

Cardiovascular failure is a significant determinant of clinical outcome, and arterial blood pressure is widely used to monitor and guide hemodynamic therapy. MAP is a central indicator of achievement related to therapy in clinical practice and is a clinical priority in treating critically ill patients (Dunser et al., 2009). In low blood pressure conditions, MAP is a better indication than systolic and diastolic blood pressure to ensure the patient's brain and other vital organs receive adequate oxygenation (Woodrow, 2004).

Based on this, the authors wanted to know whether there was a significant difference in blood pressure between using the oscillometric method and auscultation in patients in health services. PICO details are the patient population in health services with intervention in measuring blood pressure using two methods. What is compared is the measurement of blood pressure using oscillometric and auscultatory methods (aneroid sphygmomanometer). The outcome to be obtained is the result of measuring blood pressure using these two methods.

The purpose of this research are to know the value differences in the blood pressure between oscillometric and aulcultation methods of patients in health services

\section{METHODS}

The design used is a systematic review, an in-depth literature review carried out in dealing with clear questions, using a systematic and explicit method to identify, select, and critically evaluate all relevant studies, and collect and analyze data emerging from the research included in it (Abalos, E., et al., 2001). Literature or article searches were carried out independently to identify research published from January 2005 to December 2015.

Inclusion and Exclusion Criteria

a. Inclusion Criteria

1) Study type

Types of research included in the criteria are all types of research that provide intervention to the sample or experimental research with a Randomized Controlled Trial (RCT) approach.

2) Type of participant/respondent (population) 
The type of respondents taken are adults who are more than 18 years old with a setting in health services.

3) Type of intervention (multiple related interventions)

The action taken is measuring blood pressure using two measuring tools, namely oscillometric and auscultatory.

4) Type of outcome being measured. The measured result is the blood pressure value from the results of blood measurements using two different tools, namely oscillometric and auscultatory.

b. Exclusion Criteria

The type of research that is not included in the systematic review is research conducted outside of health care settings such as in the community and carried out on pediatric patients.

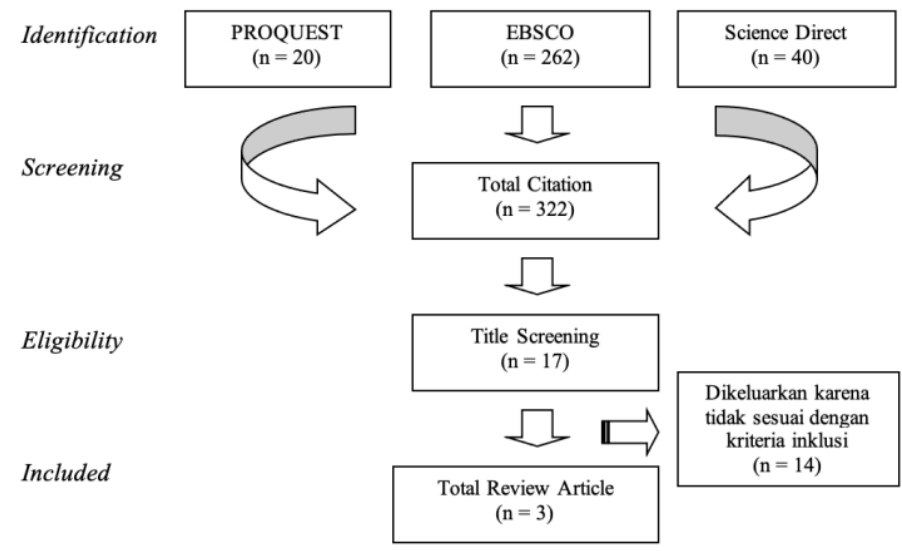

Gambar 1. Flow Chard Sintesa Systematic Review

The literature search was conducted using 3 (three) search engines: EBSCO, Proquest, and Science Direct. The articles obtained came from various health and nursing articles such as the International Journal of Nursing Practice, American Journal of Hypertension, MEDSURG Nursing, Journal of Clinical Nursing, American Journal of Hypertension, etc. The keywords used are blood pressure measurements, blood pressure read, and accurate blood pressure measurement.

Articles that meet the criteria are analyzed for critical appraisal fit with the research approach used, namely the Randomized Controlled Trial (RCT). According to the National Institute for Clinical Excellence (NICE), articles using the RCT approach have an evidence level of level Ib. 
E-ISSN: 2808-5361

http://e-journal.fkmumj.ac.id/
Proceeding The First

Muhammadiyah

Internasional- Public Health

and Medicine Conference

The measuring tool used to assess the quality of articles with the RCT approach is to use the critical appraisal skills program (CSAP). CSAP identifies literature through Screening questions; after passing through the screening questions, it can be continued through Detailed Questions. The method is to reduce the bias that exists in this Systematic Review study. The CSAP contains ten questions related to the use of RCTs in research. The data that has been analyzed is then extracted and synthesized according to the purpose.

The data obtained from the literature meets the inclusion criteria, then reviewed one by one by arranging them in a table to facilitate the review process. The table contains the name of the researcher, year of research, place of research, research method, sample and research setting, intervention, research results, level of evidence, and quality.

The form of synthesis presented in a systematic review is identification, screening, eligibility, and inclusion, and data presentation includes a flow diagram of the data results. Then, data synthesis is done by grouping similar extracted data according to the results to be measured. The data that has been collected is then looked for weaknesses and strengths and then carried out a discussion.

\section{RESULTS AND DISCUSSIONS}

A total of 3 articles on the comparison of blood pressure measurements between the oscillometric method and auscultation have been obtained.

A total of three articles were found to have intervened in the form of measuring blood pressure using oscillometric and auscultatory methods. All interventions were administered to adult patients and carried out in health services.

The intervention carried out was measuring blood pressure using oscillometric and auscultatory methods. What is compared or compared is the measurement of blood pressure using oscillometric and auscultatory methods. All interventions are given to adult patients and carried out in health services. The outcome obtained is the result of measuring blood pressure using these two methods. The results obtained in the systematic review revealed statistically significant differences in the results of blood pressure measurements in the use of two blood pressure measurement methods, namely the oscillometric and auscultatory methods. 
Table 1. Data Extraction

\begin{tabular}{|c|c|c|c|c|c|c|c|c|c|}
\hline No & Researcher Name & Year & Location & Method & $\begin{array}{l}\text { Sample, } \\
\text { setting }\end{array}$ & Intervention & Result & $\begin{array}{c}\text { Level of } \\
\text { Evidence }\end{array}$ & Quality \\
\hline 1 & $\begin{array}{l}\text { Heinemann, Megan, } \\
\text { et al }\end{array}$ & 2008 & Australia & RCT & $\begin{array}{l}\mathrm{n}=63 \text { patients, } \\
\text { General } \\
\text { treatment } \\
\text { room and } \\
\text { intensive care } \\
\text { room }\end{array}$ & $\begin{array}{l}\text { Two professional nurses conduct } \\
\text { measurement of blood pressure } \\
\text { using oscillometric method and } \\
\text { aulcultation at each respondent } \\
\text { respectively as the standard }\end{array}$ & $\begin{array}{l}\text { Finding systolic and } \\
\text { diastolic value using } \\
\text { oscillometric } \\
\text { significantly lower than } \\
\text { auscultation }\end{array}$ & $\mathrm{Ib}$ & 10 \\
\hline 2 & Bern, Linda, et al & 2007 & $\begin{array}{l}\text { Pacific } \\
\text { Norhwest }\end{array}$ & RCT & $\begin{array}{l}\mathrm{n}=483 \text { patients } \\
\text { inpatient room }\end{array}$ & $\begin{array}{l}\text { Staff who get the training, } \\
\text { conducts blood pressure } \\
\text { measurement using oscillometric } \\
\text { and auscultation method } \\
\text { respectively with the period of } \\
\text { time between } 2 \text { and } 5 \text { minutes }\end{array}$ & $\begin{array}{l}\text { Finding systolic value } \\
\text { using oscillometric } \\
\text { method has significant } \\
\text { lower value than } \\
\text { auscultation method. } \\
\text { Diastolic value which is } \\
\text { obtained by using both } \\
\text { methods did not shows } \\
\text { significant value }\end{array}$ & $1 \mathrm{~b}$ & 9 \\
\hline 3 & Suokhie, Lucy, et al & 2013 & Canada & RCT & $\begin{array}{l}\mathrm{n}=126 \text { patients } \\
\text { inpatient room }\end{array}$ & $\begin{array}{l}\text { Each respondent conducts blood } \\
\text { pressure measurement by using } \\
\text { oscillometric dan auscultation } \\
\text { methods }\end{array}$ & $\begin{array}{l}\text { The blood pressure } \\
\text { measurement by using } \\
\text { oscillometric }(\mathrm{p}<0,05) \\
\text { shows significant } \\
\text { differences. } \\
\text { Oscillometric method } \\
\text { reaches average by } 3,9 \\
\text { point higher than } \\
\text { auscultation. No } \\
\text { significant differences in } \\
\text { the diastolic reading } \\
(\mathrm{p}=0.72)\end{array}$ & $1 \mathrm{~b}$ & 8 \\
\hline
\end{tabular}

As part of the health workforce, nurses are responsible for monitoring the patient's vital signs, such as blood pressure. Measuring blood pressure is the basis for the diagnosis, treatment, and management of hypertension and is one of the documentation standards at the clinical and research level. Management decisions made are highly dependent on the accuracy of the measurements made (Wallymahmed, 2008). Measurement accuracy is essential in diagnosing and managing hypertension, planning postoperative care, and managing critically ill patients in the ICU (Buchanan et al., 2011). The auscultatory measurement method using a mercury sphygmomanometer or auscultation has been used in the clinical setting for more than 100 years and is now being replaced by automated methods. The oscillometric method is currently the most frequently used. However, whatever measuring instrument is used, it must be continuously validated, maintained regularly, and recalibrated.

The results shown in the literature study of three articles show a statistically significant difference in systolic pressure using the two blood measurement methods. Two articles showed that statistically, systolic pressure was lower on the oscillometric method than on auscultation. Another article showed that the systolic pressure on the oscillometric method was higher than on auscultation.

Blood pressure naturally varies in value from time to time. Several factors that can vary the value are emotion, digestion, exercise, smoking, alcohol, temperature, breathing, urinary distention, and pain. Blood pressure values also tend to fall during sleep (Pickering et al., 2005; Valler-Jones and Wedgbury, 2005). Age, race, and general health status also affect blood pressure. Therefore, these factors must be considered when recording and managing blood pressure (Timby, 2012; Beevers et al., 2014). 
Blood pressure measurement should be carried out as accurately as possible using both auscultation and oscillometric (O'Brien et al., 2003). Pickering et al., 2005 explained that the auscultation method is based on the sound produced by blood flow through the arteries covered by the cuff on the patient's arm. The sound is often referred to as Korotkoff, which clinicians hear using a stethoscope. The variability between the use of auscultation and oscillometric methods depends on the clinician's skill, hearing sensitivity, and environmental noise. The main reason that oscillometric has better assessment is that the human ear can only pick up sound, no vibrations. Vibration in the arteries usually occurs before the sound manifests. Thus, when the nurse listens to Korotkoff's voice, the systolic pressure may occur first.

Although there are still concerns about using oscillometric devices for blood pressure measurement in various cases, the use of oscillometric is still being used. Suggestions that can be used are to use the two methods in some situations. Nurses can screen patients who need blood pressure measurements with a high degree of accuracy. Patients in this group, for example, patients with hypertension. It should also be noted that from the studies reviewed, those using sphygmomanometers were specifically trained, whereas clinical nurses may not have sufficient training or experience to take measurements accurately. Proper education to ensure measurement accuracy, which device to use. Additional relevant professional education and more rigorous examination of practice may be required to ensure safe and effective clinical care.

\section{CONCLUSION}

Blood pressure measurement is the basis for the diagnosis, treatment, and management of hypertension and is one of the documentation standards at the clinical and research level. Management decisions made are highly dependent on the accuracy of the measurements made. The use of both methods is recommended in some cases that require a high degree of accuracy.

\section{REFERENCES}

Abalos, E., et al (2001). Critical Appraisal of Systematic Reviews. Geneva: The WHO Reproductive Health Library

Ballie L. (2005). Developing Practical Nursing Skills. London: Hodder Arnold,

Beevers G, Lip G \& O’Brien E. (2001). ABC of hypertension: BP measurement. PartI. sphygmomanometry: factors common to all techniques. British Medical Journal 322, 981-985. 
E-ISSN: 2808-5361

http://e-journal.fkmumj.ac.id/
Proceeding The First

Muhammadiyah

Internasional- Public Health and Medicine Conference

Dünser MW, et al. (2009. Arterial blood pressure during early sepsis and outcome. Intensive Care Medicine. 35 (7): 1225-1233.

Edmonds ZV, et al. (2002.)The reliability of vital sign measurements. Ann Emerg Med, 39(3): 233-37.

Hinckley P, Walker S (2005) Measuring blood pressure. Practice Nurse. 29, 9, 5461.

Jones CA, et al. (2001). Using survival analysis to explore female cardiac rehabilitation program adherence. Appl Nurs Res. 14(4):179-186.

Medicines and Healthcare Products Regulatory Agenc. (2006). Device Bulletin: Blood Pressure Measuring Devices. Available http://www.mhra.gov.uk/Publications/Safetyguidance/DeviceBulletins/CON2025142 (accessed 26 September 2015)

Medicines and Healthcare Products Regulatory Agency. (2003). Minutes of the Meeting of the Committee On Blood Pressure Monitoring In Clinical Practice, Tuesday, 4 November 2003. Available

at: http://www.mhra.gov.uk/Committees/Devices/CommitteeonBloodPressureMonitoringinC linicalPractice/index.htm (accessed 26 September 2015)

Pickering TG, et al. (2005). AHA scientific statement. recommendations for blood pressure measurement in humans and experimental animals. Part 1:Blood pressure measurement in humans. A statement for professionals from the subcommittee of professional and public education of the American heart association council on high blood pressure research. Hypertension 45(1): 142-61., 2005 Recommendations for blood pressure measurement in humans and experimental animals. Circulation;111:697-716.)

Valler-Jones T, Wedgbury K. (2005). Measuring blood pressure using the mercury sphygmomanometer. Br J Nurs 14(3):145-150

Wedgbury K, Valler-Jones T. (2008). Measuring blood pressure using an automated sphygmomanometer. Br J Nurs 17(11): 714-8

Woodrow P. (2004). Assessing blood pressure in older people. Nursing Older People. 16, 1, 29-31 